\title{
OPPONENT-PROCESS ADDITIVITY-III.
}

\section{EFFECT OF MODERATE CHROMATIC ADAPTATION ${ }^{1}$}

\author{
Carol M. Cicerone and David H. Krantz \\ Department of Psychology, University of Michigan. 330 Packard Road. \\ Ann Arbor, Michigan 48104, U.S.A. \\ and \\ JAMES LARIMER \\ Department of Psychology, Temple University, Philadelphia, Pennsylvania 19122. U.S.A.
}

(Received 18 November 1974; in revised form 3 February 1975)

\begin{abstract}
The luminance invariance and additivity of opponent-color equilibria were tested under conditions of chromatic adaptation to unique blue, green, yellow and to (nonunique) $650 \mathrm{~nm}$ red lights, varying from about 40 to $2000 \mathrm{td}$. Although the adapting lights produced large shifts in the loci of the red/green equilibrium colors away from their dark-adapted values, hardly any nonadditivity was produced by blue or green adaptation. For yellow adapting lights of 900 td or more, the red/green equilibria are luminance dependent, hence nonadditive. A small luminance dependence was produced by $40 \mathrm{td}$ red adaptation. As a first approximation, the effects of moderate chromatic adaptation on the red/green opponent code can be described by a coefficient law; however, the fact that unique hues do not shift under moderate self-adaptation implies that the coefficient for at least one receptor type depends on the adapting input to other receptor types. The fact that yellow and red adaptation make the dark determined unique blue wavelength look reddish implies that the short-wavelength cones contribute a red input to the red/green opponent system. The yellow/blue system exhibited nonlinearities under chromatic adaptation which were qualitatively similar to the nonlinearities found under dark adaptation.
\end{abstract}

In two preceding papers we investigated Grassmanntype additivity laws for the equilibrium colors of the red/green and yellow/blue opponent processes, for dark-adapted foveal vision. The equilibrium colors for the red/green process (i.e. unique yellow, unique blue, and achromatic colors) were found to satisfy additivity (see Larimer, Krantz and Cicerone, 1974). That is, suppose $a$ is a yellow light which appears neither reddish nor greenish, and $b$ is a blue light which also appears neither reddish nor greenish. Then the linear combination, $(s * a) \oplus(t * b)$, is another red/green equilibrium light. (The combination will appear yellowish, achromatic, or bluish, depending on the ratio $s / t$.)

The implication of such a finding is that the condition of red/green equilibrium can be described as the zero-point of a linear function, denoted $\phi_{1}$. That is, $\phi_{1}(a)$ is the red/green chromatic response (Jameson and Hurvich, 1955); it is measured by cancelling redness (greenness) by admixture of a standard green (red) light, $a$ is a red/green equilibrium if and only if $\phi_{1}(a)=0$; and $\phi_{1}$ is linear. Linearity means that $\phi_{1}[(s * a) \Theta(t * b)]=s \phi_{1}(a)+t \phi_{1}(b)$. Moreover it can be proved (Krant, 1975a) that $\phi_{1}$ is consequently a linear combination of the three photopigment

'This research was supported by N.S.F. grants GB 8181 and GB 36642-X to the University of Michigan. The senior author acknowledges predoctoral support through N.I.H. grant GM-01231 to the University of Michigan.

2 Equation (1) allows for $k_{\mathrm{t} 1}=0$; however, the results to be reported are interpreted as meaning that $k_{11}>0$, i.e. the $\alpha$ or short-wavelength cones contribute a red input to the red/green opponent system.

v.R. $15 \cdot 11:-F$ quantum-catch functions. That is, if $\alpha(a), \beta(a)$, and $\gamma(a)$ denote the quantum-catch rate from light $a$, for the short-, medium- and long-wavelength cone types respectively, then

$$
\phi_{1}(a)=k_{11} x(a)-k_{12} \beta(a)+k_{13} \gamma(a) .
$$

Here, $k_{11},-k_{12}$ and $k_{13}$ denote the signed weighting coefficients for the contributions of $\alpha, \beta$, and $\gamma$ cones to the red/green chromatic-response function. ${ }^{2}$

We emphasize that equation (1) is not merely a hypothesis about opponent-color cancellation and equilibrium; rather, it is a mathematical consequence of the empirically verified Grassmann-type additivity laws. (For proof, see Krantz, 1975b. Similarly, the corresponding linear equation relating color-matching functions to cone quantum-catch functions is a logical consequence of Grassmann's laws of metameric matching; see Brindley, 1960 and Krantz, 1975a.)

This additivity finding prompted us to repeat the additivity tests under conditions of chromatic adaptation. If one adapts to a green light of moderate intensity, lights which previously looked neither reddish nor greenish will appear quite reddish (orange, pink or violet, depending on whether they previously looked yellow, white or blue). New equilibrium lights can be found, which to the dark-adapted eye looked greenish yellow, greenish white or greenish blue. The question is, does this new set of red/green equilibrium lights satisfy the same additivity properties? If it does, then precisely the same mathematical reasoning will lead us to a new equation describing the adapted chromatic-response function:

$$
\phi_{1}(a ; c)=k_{11}(c) \alpha(a)-k_{12}(c) \beta(a)+k_{13}(c),(a) .
$$


In this equation. $c$ denotes the adapting light and $k_{11}(c),-k_{12}(c), k_{13}(c)$ are the new weighting coefficients. The effects on the redgreen equilibria of adapting to $c$ would then be completely described by the shift from $k_{1 j}$ (equation (1)) to $k_{1}$ (c) (equation (2)). In particular the shift in the equilibrium locus is independent of the luminance of the test stimulus. Such a finding would open up a new set of questions: how does $k_{1} f(c)$ vary as a function of $c$ ?

Chromatic adaptation may have a number of different effects. depending on temporal, spatial, and intensity parameters. In hopes of tapping a relatively unitary process of chromatic adaptation, we first employed adapting exposures that were long and relatively $\operatorname{dim}(40 \mathrm{td})$. This probably eliminates photopigment bleaching as a significant source for the adapting signal.

Clearly the questions raised here are closely related to those posed in previous work on chromatic adaptation (e.g. MacAdam, 1956; Burnham, Evans and Newhall, 1957; Hurvich and Jameson, 1958; Wooten, 1970). However, these previous studies principally involved measurements of the appearance of nonequilibrium colors. Thus, to make a connection with our work, we must specify the relationship between norzero values of $\phi_{1}(a ; c)$ (in equations (2) or (3), e.g.) and the redness or greenness of nonequilibrium colors. However, the chromatic-response function, $\phi_{1}$, is constructed solely on the basis of equilibrium observations (cancellation); and its quantitative relation to nonequilibrium color appearance is one of the most important unsolved problems of color theory. So the relationships between the present study and the ones cited must be discussed very carefully. In particular, it is not true that additivity in our study, with its consequent coefficient changes, $k_{i j} \rightarrow k_{i j}(c)$, would imply that a coefficient law holds for asymmetric matching. We shall return to this point in the discussion.

\section{METHOD}

\section{Design}

In the main experiment, designated Experiment I, five conditions of adaptation were employed: dark, blue, green, yellow and red. The dark-adapted condition simply replicated experiments reported in our previous papers. The blue, green, and yellow adapting lights were monochromatic, chosen for each observer at the wavelengths of the dark-adapted spectral equilibrium loci. This was done on the basis of pilot data, collected during a fairly extensive practice period prior to the main experiment. (Such practice was required because of the perceptual learning necessary to respond in a stable fashion to slight deviations from equilibrium.) The red adapting light was simply chosen at $650 \mathrm{~nm}$. (Since equilibrium red is extraspectral, it would have required two monochromators for the adapting field.) The experiment consisted of 16 light-adapted sessions with interspersed dark-adapted sessions. Four sessions were devoted to each of the adapting colors. For observers $\mathrm{CC}$ and TC, pilot dark-adapted values did not differ from the ones obtained in our previous experiments. Observers DK and PS showed a change in one equilibrium locus (green and blue, respectively). A total of four or five darkadapted sessions were interspersed among the lightadapted ones, to keep track of any further shifts (none occurred).

For each adaptation condition. there were three parts to the experiment: (i) measurement of the spectral loci of the red green equilibria: (ii) mixture tests for the red green equilibria : and (iii) measurement of the yellow blue equilibria. The logical part livi. mixture tests for vellow blue equilibria, was omitted. because it required four channels. only three of which were available in the apparatus.

In each of parts (i) and (iii). there were eight test conditions: four test-luminance levels times two equilibrium colors. The lowest test luminance was approximately equal to the adapting luminance (about 40 td): the remaining three levels were approx 05.10 , and $1.5 \log _{10}$ units above it.

In part (ii) we determined red/green equilibria composed of mixtures of a yellowish wavelength and a bluish wavelength. For each test condition, we fixed both the yellowish wavelength and the yellow/blue luminance ratio, and we determined the wavelength of the bluish component of the mixture necessary for red/green equilibrium. In any given session, three fixed yellowish wavelengths were used: these consisted of the estimated equilibrium yellow wavelength as determined in part (i) earlier in the same session. and two wavelengths, one a fixed amount longer and the other a fixed amount shorter than the equilibrium yellow. The rationale for using wavelengths displaced from the equilibrium point is explained in Larimer et al. (1974, pp. 11311132). Since there was variation in the daily determinations of equilibrium yellow, a large number of different conditions were explored over sessions. Two different yellow/ blue luminance ratios of 2.0 and 6.8 were used (for observer PS only one ratio was used by mistake). The retinal illuminance of the yellow component was fixed near 230 td and two different illuminances of the blue were used, about 115 and 33.9 td.

In part (iii). for the extraspectral red, the luminance ratio of the red $(650 \mathrm{~nm})$ to the blue was fixed at 3.0 and the wavelength of the blue component was varied.

In Experiment II, performed after the completion of Experiment I. we tested the effects of higher luminance adapting fields. We determined the loci of the red/green equilibrium hues under green adaptation at intensities of 39,438 and 2461 td: under blue adaptation of 39 and 480 td; and under yellow adaptation of 39.663 and $3900 \mathrm{td}$.

\section{Apparatus}

The apparatus and calibration were the same as previously described (Larimer et al., 1974). In the present experiment the test stimuli were either a single monochromatic beam or mixtures of two monochromatic beams, provided by $55-\mathrm{mm}$ grating monochromators with appropriate stray-light filters. The field was a dise, $2.6^{\circ}$ in visual angle, seen foveally in Maxwellian view. The adapting stimulus was provided by a small monochromator (also with appropriate stray-light filters) and was also $2 \cdot 6^{\circ}$ and presented foveally in Maxwellian view.

\section{Adaptation procedure}

The observer initially fixated the adapting disc for at least $5 \mathrm{~min}$. Subsequently, the adaptation channel was occluded for $1 \mathrm{sec}$, during which the test stimulus was exposed with no change in fixation. The test stimulus terminated and the adapting stimulus immediately reappeared for $20 \mathrm{sec}$. The experiment continued with a 21 -sec cycle, $20 \mathrm{sec}$ of readapting exposure followed by $1 \mathrm{sec}$ test exposure. After short breaks. the observer initially readapted for at least $60 \mathrm{sec}$ (usually longer). The adequacy of adaptation maintenance was obvious, since there was no tendency whatever for subjects to shift systematically over the course of the block of test trials following a break or at the start of an experimental session.

\section{Test procedure}

For each experimental condition, a staircase method was used to determine the equilibrium wavelength, or the wavelength of one component of an equilibrium mixture. For example, in part (i), for the measurement of the red/green 
equilibrium wavelength in the blue region of the spectrum, the observer judged each stimulus as reddish or greenish. The wavelength of the next stimulus on the staircase was accordingly moved one step toward longer (blue-green) or shorter (violet) wavelengths. The same method was used in part (ii), except that a fixed yellow wavelength was present in each test stimulus on the staircase, and consequently, the test stimulus appeared whitish, rather than a saturated blue. In part (iii) a fixed red wavelength $(650 \mathrm{~nm})$ was present, and the subject judged the red-plus-blue mixture as yellowish or bluish. For more details concerning the rationale of these methods, see Larimer et al. (1974, 1975).

Each experimental session of Experiment I comprised three sections, corresponding to parts (i), (ii) and (iii) of the design. Since the estimates of the yellowish equilibrium locus in part (i) were used to determine the addends in the mixture experiment part (ii). part (i) always preceded part (ii); otherwise, the order was varied in a nearly counterbalanced way.

In sections (i) and (iii), the staircases corresponding to the eight conditions were irregularly interspersed, so that the subject could not anticipate which staircase would determine the next test stimulus. (To simplify running we generally employed blocks of 8-12 stimuli in one spectral region, but that still involved alternation among at least three staircases.) In some experimental sessions only three of the four luminance levels were used in a given spectral region (in particular, the decision to add the highest luminance level was made after the experiment was well under way for two observers. CC and TC). In section (ii), for any session, one of the two yellow/blue luminance ratios was selected, and three different staircases. corresponding to different wavelengths of the yellow addend, were interspersed. One of the three wavelengths was the daily estimate of the equilibrium locus for yellows; a second was of shorter and a third of longer wavelength (by $3-5 \mathrm{~nm}$ for high yellow/blue ratio and by $8-10 \mathrm{~nm}$ for low yellow/blue ratio).

\section{Observers}

The observers were four of the five employed in our previous experiments (CC, DK, TC and PS). Only CC was used in Experiment II.

\section{RESULTS OF EXPERMENT}

\section{Part (i): red/green equilibrium loci}

Table 1 shows the estimated mean and the halfwidth of the $80 \%$ confidence interval for the red/green equilibrium wavelengths, in the yellow and blue spectral regions, as a function of observer, adapting condition, and test luminance. The results for one observer, $\mathrm{CC}$, are plotted in Fig. 1. We refer to the figure in pointing out significant features of the results; the reader can verify from the table that the main qualitative features are confirmed for the other three observers.

The dark-adapted data for CC were taken from Larimer et al. (1974); the sessions run in the present experiment did not differ from these previous results. We concluded in that previous paper that these data did not show any substantial deviation from the prediction on the basis of additivity: namely, that the equilibrium locus is independent of luminance level. Note that blue adaptation leaves both this additivity property and the actual equilibrium locus invariant in the blue region of the spectrum. The additivity property is also preserved in the yellow region, but the spectral equilibrium locus is shifted $9 \mathrm{~nm}$ toward

Table 1. Equilibrium colors of the red/green opponent process

\begin{tabular}{|c|c|c|c|c|c|c|c|c|c|c|}
\hline \multirow{3}{*}{\multicolumn{2}{|c|}{ subject }} & \multicolumn{9}{|c|}{ Adepting Condition } \\
\hline & & \multirow{2}{*}{$\frac{\text { Dark }}{\ell_{0}}$} & \multicolumn{2}{|r|}{ Blue } & \multicolumn{2}{|r|}{ Green } & \multicolumn{2}{|r|}{ Yollow } & \multicolumn{2}{|r|}{ Red } \\
\hline & & & $\log 1$ & $t_{0}$ & 1081 & $x_{0}$ & $\log 1$ & $x_{0}$ & $\log 1$ & $x_{e}$ \\
\hline \multirow{4}{*}{ 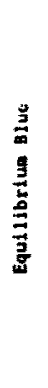 } & or & $\begin{array}{l}478.3 \\
478.4 \\
476.9 \\
477.1\end{array}$ & $\begin{array}{r}.93 \\
.54 \\
.08 \\
. .37\end{array}$ & $\begin{array}{l}479.3 \pm 2.6 \\
479.3 \pm 2.6 \\
479.5 \pm 2.4 \\
478.5 \pm 1.1\end{array}$ & $\begin{array}{r}1.08 \\
.49 \\
.05 \\
-.42\end{array}$ & $\begin{array}{l}488.4 \pm 3.0 \\
490.9 \pm 2.1 \\
490.4 \pm 0.5 \\
492.2 \pm 1.0\end{array}$ & $\begin{array}{r}1.00 \\
.52 \\
.06 \\
-.39\end{array}$ & $\begin{array}{l}483.4 \pm 3.8 \\
484.0 \pm 3.7 \\
486.5 \pm 2.9 \\
485.9 \pm 1.3\end{array}$ & $\begin{array}{r}1.06 \\
.53 \\
.08 \\
-.37\end{array}$ & $\begin{array}{l}486.912 .3 \\
482.1 \pm 1.9 \\
481.594 .4 \\
480.3 \div 2.2\end{array}$ \\
\hline & $\pi$ & $\begin{array}{l}478.5 \\
478.0 \\
474.4\end{array}$ & $\begin{array}{r}.53 \\
.57 \\
.07\end{array}$ & $\begin{array}{c}-\bar{c} \\
479.3 \pm 1.1 \\
477.5 \pm 1.3 \\
475.8 \pm 1.0\end{array}$ & $\begin{array}{r}1.10 \\
.49 \\
.05 \\
. .40\end{array}$ & $\begin{array}{r}491.8 \pm 1.3 \\
990.2 \pm 1.8 \\
489.5 \pm 1.2 \\
490.0 \pm 1.7\end{array}$ & $\begin{array}{r}1.16 \\
.42 \\
.06 \\
. .39\end{array}$ & $\begin{array}{l}494.7 \pm 3.6 \\
489.0 \pm 3.2 \\
487.024 .6 \\
487.7 \pm 6.5\end{array}$ & $\begin{array}{r}1.05 \\
.54 \\
.08 \\
-.40\end{array}$ & $\begin{array}{l}486.1 \pm 5.2 \\
478.9 \pm 6.7 \\
478.8 \pm 5.1 \\
474.6 \pm 5.7\end{array}$ \\
\hline & PS & $\begin{array}{l}492.7 \\
489.4 \\
489.4 \\
488.2\end{array}$ & $\begin{array}{r}1.12 \\
.48 \\
.06 \\
-. .39\end{array}$ & $\begin{array}{l}491,3 \pm 1.6 \\
491,3 \pm 1.6 \\
487,5 \pm 0.7 \\
486.1 \pm 1.7\end{array}$ & $\begin{array}{r}1.17 \\
.47 \\
.03 \\
-.41\end{array}$ & $\begin{array}{l}495.7 \pm 1.0 \\
493.2 \pm 0.9 \\
491.7 \pm 1.0 \\
491.5 \pm 1.2\end{array}$ & $\begin{array}{r}1.17 \\
.47 \\
.03 \\
-.42\end{array}$ & & $\begin{array}{r}1.15 \\
.47 \\
.40 \\
-.39\end{array}$ & $\begin{array}{l}493.9 \pm 1.4 \\
492.9=0.4 \\
490.9 \pm 1.9 \\
487.9 \pm 0.4\end{array}$ \\
\hline & 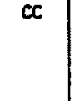 & $\begin{array}{l}478.8 \\
479.0 \\
478.8 \\
476.8\end{array}$ & $\begin{array}{r}.95 \\
.54 \\
.09 \\
. .38\end{array}$ & $\begin{array}{l}479.7 \pm 2.7 \\
479.0 \pm 0.8 \\
480.0 \pm 1.7 \\
478.3 \pm 1.8\end{array}$ & $\begin{array}{r}1.11 \\
.30 \\
.06 \\
-.40\end{array}$ & $\begin{array}{r}490.5 \pm 3.3 \\
488.4 \pm 1.7 \\
488.1 \pm 0.8 \\
489.9 \pm 1.5\end{array}$ & $\begin{array}{r}1.15 \\
.08 \\
.04 \\
-.45\end{array}$ & $\begin{array}{l}493.8 \pm 1.7 \\
491.4 \pm 2.3 \\
491.5 \pm 11.5 \\
496.9 \pm 2.0\end{array}$ & $\begin{array}{r}1.09 \\
.51 \\
.06 \\
-.30\end{array}$ & $\begin{array}{l}489.2 \pm 2.3 \\
487.6 \pm 1.4 \\
486.8 \pm 1.9 \\
486.3 \pm 2.8\end{array}$ \\
\hline \multirow{4}{*}{ 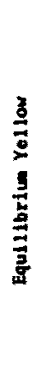 } & $D x$ & $\begin{array}{l}576.8 \\
574.4 \\
574.7 \\
574.0\end{array}$ & $\begin{array}{r}1.29 \\
.72 \\
.25 \\
-.20\end{array}$ & $\begin{array}{l}561.0 \pm 2.4 \\
552.2 \pm 4.6 \\
550.2 \pm 4.2 \\
550.2 \pm 4.7\end{array}$ & $\begin{array}{r}1.29 \\
.72 \\
.25 \\
-.26\end{array}$ & $\begin{array}{l}560.3 \pm 2.2 \\
552.8 \pm 3.2 \\
550.9 \pm 3.0 \\
543.6 \pm 2.9\end{array}$ & $\begin{array}{r}1.21 \\
.71 \\
.25 \\
-.21\end{array}$ & $\begin{array}{l}577.1 \pm 2.3 \\
576.5 \pm 1.5 \\
577.3 \pm 1.0 \\
574.6 \pm 1.3\end{array}$ & $\begin{array}{r}1.20 \\
.72 \\
.26 \\
-.29\end{array}$ & \\
\hline & $\pi$ & $\begin{array}{l}568.4 \\
567.3 \\
569.8\end{array}$ & $\begin{array}{r}1.12 \\
.57 \\
.13 \\
-.33\end{array}$ & $\begin{array}{l}538.6 \pm 5.9 \\
532.3 \pm 6.2 \\
534.6 \pm 6.8 \\
532.8 \pm 5.0\end{array}$ & $\begin{array}{r}1.08 \\
.58 \\
.11 \\
-.33\end{array}$ & $\begin{array}{l}\$ 32.2 \pm 6.4 \\
535.0 \pm 5.5 \\
531.2 \pm 6.2 \\
532.6 \pm 3.2\end{array}$ & $\begin{array}{r}1.27 \\
.76 \\
.29 \\
-.17\end{array}$ & $\begin{array}{l}565.5 \pm 2.2 \\
565.6 \pm 1.2 \\
565.6 \pm 1.0 \\
566.3 \pm 1.2\end{array}$ & $\begin{array}{r}1.24 \\
.74 \\
.29 \\
-.25\end{array}$ & $\begin{array}{l}592.7 \pm 6.8 \\
597.8 \pm 3.2 \\
599.8 \pm 3.3 \\
604.2 \pm 2.0\end{array}$ \\
\hline & PS & $\begin{array}{l}570.3 \\
574.2 \\
573.3 \\
573.7\end{array}$ & $\begin{array}{r}1.28 \\
.76 \\
.31 \\
-.13\end{array}$ & $\begin{array}{l}562.0 \pm 1.8 \\
564.9 \pm 2.8 \\
563.8 \pm 3.0 \\
561.1 \pm 2.0\end{array}$ & $\begin{array}{r}1.28 \\
.77 \\
.31 \\
-.33\end{array}$ & $\begin{array}{r}562.2 \pm 1.9 \\
563.6 \pm 1.0 \\
563.2 \pm 0.8 \\
563.4 \pm 0.4\end{array}$ & $\begin{array}{r}1.24 \\
.72 \\
.29 \\
-.21\end{array}$ & $\begin{array}{l}571.4 \pm 1.2 \\
574.1 \pm 1.0 \\
575.1 \pm 1.2 \\
574.1 \pm 0.8\end{array}$ & $\begin{array}{r}1.22 \\
.74 \\
.26 \\
-.15\end{array}$ & $\begin{array}{l}583.1 \pm 2.3 \\
588.6 \pm 3.5 \\
588.1 \pm 4.2 \\
591.4 \pm 4.2\end{array}$ \\
\hline & $c c$ & $\begin{array}{c}. \\
577.1 \\
578.1 \\
580.7\end{array}$ & $\begin{array}{r}1.24 \\
.74 \\
.27 \\
-.20\end{array}$ & $\begin{array}{l}571.3 \pm 1.1 \\
568.4 \pm 1.3 \\
570.0 \pm 1.7 \\
570.3 \pm 1.9\end{array}$ & $\begin{array}{r}1.22 \\
.74 \\
.26 \\
-.19\end{array}$ & $\begin{array}{l}575.5 \pm 3.0 \\
568.4 \pm 1.3 \\
568.1 \pm 2.7 \\
569.3 \pm 5.1\end{array}$ & $\begin{array}{r}1.21 \\
.70 \\
.24 \\
-.22\end{array}$ & $\begin{array}{l}580.5 \pm 1.7 \\
580.1 \pm 0.2 \\
579.6 \pm 1.3 \\
577.5 \pm 0.8\end{array}$ & $\begin{array}{r}1.17 \\
.65 \\
.09 \\
-.35\end{array}$ & $\begin{array}{l}603.0 \pm 2.6 \\
604.0 \pm 1.2 \\
608.9 \pm 1.7 \\
615.6 \pm 1.7\end{array}$ \\
\hline
\end{tabular}

$\lambda_{e}$ is the mean equilibrium wavelength ( \pm halfwidth of $80 \%$ confidence interval). $\log I$ is the logarithm of the retinal illumination (relative to $115 \mathrm{td})$. Adapting luminance is about $40 \mathrm{td}$. 


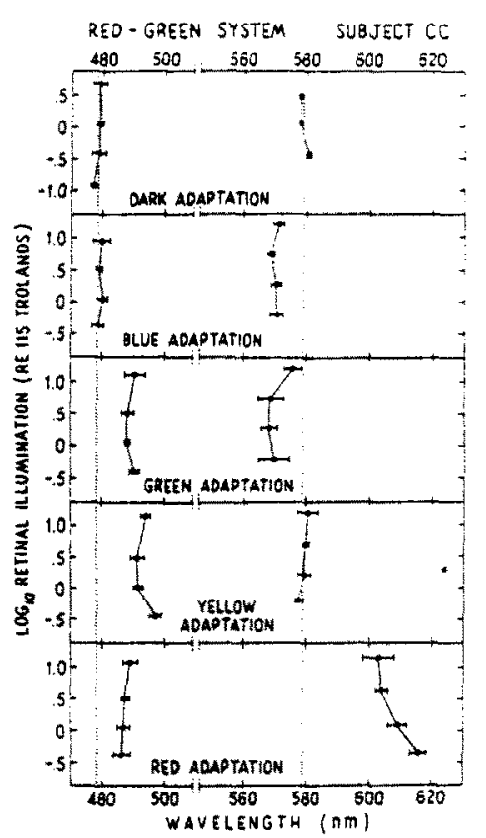

Fig. 1. The mean values of equilibrium blue (left) and equilibrium yellow (right) spectral loci under dark adaptation and 40 td of equilibrium blue adaptation equilibrium green adaptation, equilibrium yellow adaptation and red $(650 \mathrm{~nm})$ adaptation are shown for subject $\mathrm{CC}$. The error bars are 80 per cent confidence intervals based on betweensession variability. The dotted lines mark the mean values of the dark-adapted equilibrium wavelengths. Note the break in the wavelength abscissa between 500 and $560 \mathrm{~nm}$.

shorter wavelengths for observer $\mathrm{CC}$. The shifts for the other three observers are in the same direction, but are larger. Under blue adaptation, the former equilibrium yellow looks orange. But this is not merely a negative orange afterimage, adding to the yellow. If this were the case, the afterimage would produce a shift at the lowest luminance level, but would be swamped by the brightest test luminance. Instead all luminance levels tested show about the same shift (additivity prediction). The same luminance invariance is found for all four observers. for equilibrium yellow under blue adaptation, except that for DK, the very highest test luminance yields a smaller shift.

Under green adaptation, the additivity property is again reasonably preserved, but now both spectral loci shift toward the adapting wavelength; the darkadapted blue and yellow loci look reddish blue and reddish yellow. Again, the effect of green adaptation cannot be treated as a red afterimage, since for three observers, the luminance invariance is satisfied. (It is violated for DK in the yellow region; we are at a loss to explain this difference.)

Under yellow adaptation, additivity properties still hold; now it is the yellow locus which is fixed, and the blue one which shifts. The dark adapted equilibrium blues look violet under yellow adaptation. Once more, the new equilibrium-blue locus is independent of luminance (there is a nonsignificant trend toward a larger shift with higher test luminance).

Finally, the red adapting light shows the only failure of linearity which is reproducible across subjects: the shift of the yellow equilibrium point is greater for low test luminances than for high ones. This is true for all four observers. Yet it is important to note that the change with luminance is only $13 \mathrm{~nm}$ for $C C$, while even the highest luminance test field is shifted $14 \mathrm{~nm}$ from its dark-adapted equilibrium wavelength. A comparable result holds for PS, while for DK and TC. the luminance shifts are much smaller compared with the shifts produced by adaptation. One might suppose that red adaptation involves an additional adapting mechanism (e.g. an afterimage), which does not come strongly into play for the other adapting conditions. Note also the nature of the effect of red adaptation in the blue region: luminance invariance is maintained and the former equilibrium blue looks reddish blue after red adaptation! The effects of red adaptation and of yellow adaptation on the blue equilibrium locus are generally similar. The only explanation for these results that has occurred to us is to assume that red and yellow adaptation leave the outputs of the short-wavelength $(x)$ cones relatively enhanced, and that this enhanced output provides a blue input to the yellow/blue opponent system and a red input to the red/green opponent system. A quantitative discussion of this explanation is deferred to the discussion section.

\section{Part (ii): redigreen equilibrium mixtures}

Table 2 gives the coordinates of red/green equilibrium mixtures, as a function of observer, adapting condition and yellow/blue luminance ratio. The extensive dark-adapted data (Larimer et al., 1974, Fig. 5) are not repeated here. The first coordinate is the wavelength of the yellow component, which was fixed during any measurement; the second is the estimated wavelength of the blue component, based on a single staircase.

Figure 2 plots the data for observer $\mathrm{CC}$. The open symbols are the points for yellow/blue ratio equal to 2.0 . the closed symbols represent a ratio of 6.8 . The large star on each graph represents the mean spectral loci for equilibrium yellow and blue, as found in part (i). As shown previously (Larimer et al, 1974) the additivity prediction is that the curves for different yellow/blue ratios should intersect at the large star. The departures from additivity are no larger than found in Larimer et al. (1974) under dark-adapted conditions. These departures are nonsystematic and visually trivial.

\section{Part (iii): yellow/blue equilibria}

Table 3 and Fig. 3 display the results for the equilibria of the yellow/blue opponent process. The data for "equilibrium red" are the wavelengths of the blue component the red component being fixed at $650 \mathrm{~nm}$.

The first indication of nonadditivity in our darkadapted study (Larimer et al., 1975) was the tendency for the observer to need less blue for equilibrium red as luminance increased. This was not very clearcut for observer $\mathrm{CC}$, whose data are replotted in Fig. 3, but it was consistent over observers and was repeatedly confirmed in the data for mixtures of reddish and greenish equilibria. We see that this same shift is found for all four light-adapted conditions for CC, and the data from the other observers corroborate the finding. The size of the shift does not seem to vary in any regular or reproducible way as a function of adaptation. 
Table 2. Loci of yellow plus blue mixtures that are neither reddish nor greenish

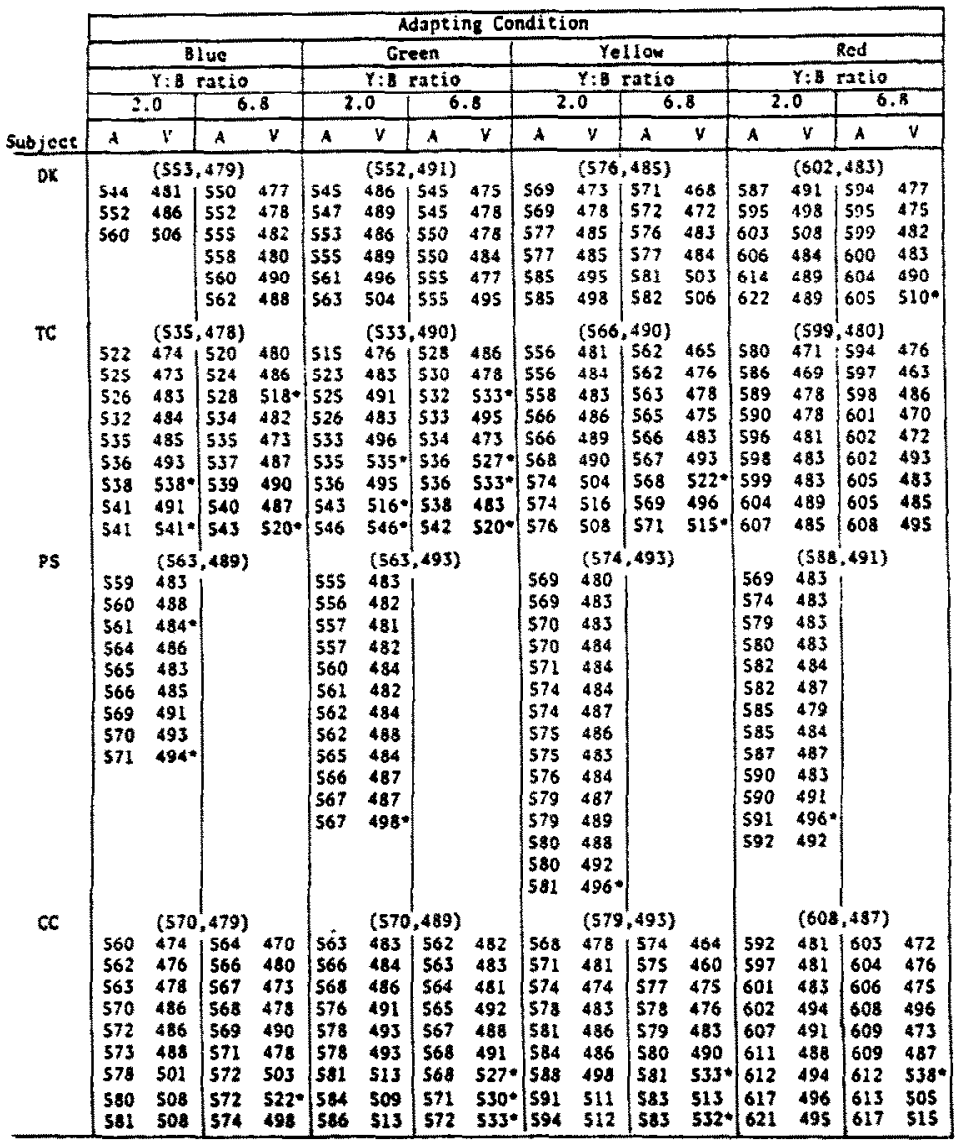

Two yellow:blue ratios of approx 2.0 and 6.8 were used. $A$ is the wavelength of the fixed yellow addend which when combined with a variable blue light of wavelength $V$ produced a red/green equilibrium mixture. Each pair $A, V$ is based on a single day's determination. Poorly determined points are marked with an asterisk. In parentheses are the mean spectral loci for equilibrium yellow and blue as found in part (i) under $40 \mathrm{td}$ of blue, green, yellow and red adaptation.

The equilibrium-green locus remains unchanged under green adaptation. For CC (Fig. 3) blue adaptation induces a shift of approx $8 \mathrm{~nm}$ toward shorter wavelengths; yellow adaptation induces an $11-\mathrm{nm}$ shift; and red adaptation yields a small shift of less than $5 \mathrm{~nm}$. In all cases but blue, these shifts are accompanied by strong support for linearity. There is a slight but apparent deviation from linearity under blue adaptation in the consistent progression of the equilibrium green locus toward shorter wavelengths as test intensity decreases.

For dark-adapted conditions (Larimer et al., 1975) the locus of the short-wavelength component of equilibrium red is always well below the equilibriumgreen point; this reflects the fact that the $650-\mathrm{nm}$ light is perceived as yellowish red and a bluish light must be added to attain yellow/blue equilibrium. This effect was smallest for CC. For two observers (DK, TC) the same effect was found in all the light-adapted conditions, even after yellow adaptation. (Note that for these observers, the yellow-adapted equilibrium red had its short-wave component approximately at the dark-adapted value of equilibrium green.) For CC, the effect is small under dark and red adaptations and more or less disappears for the other conditions. The data of PS are rather irregular; they clearly fail to show the effect in question.

\section{RESULTS OF EXPERIMENT II}

The present experiments have shown that the properties of luminance invariance and additivity of opponent-process equilibria are preserved under low levels of chromatic adaptation. At the same time, the linear codes $\phi_{1}$ and $\phi_{2}$ which represent the conditions for additivity are changed dramatically, as is evidenced by shifts of the equilibrium hue loci on the wavelength axis. But the findings thus far hold only for low adapting levels, near $40 \mathrm{td}$. Additional experiments with observer $\mathrm{CC}$ investigated the effects of higher levels of adaptation.

Figure 4 shows that linearity was maintained for 1.59 and $2.68 \mathrm{log}$ td of blue adaptation. Again, the equilibrium blue locus was hardly shifted from its 


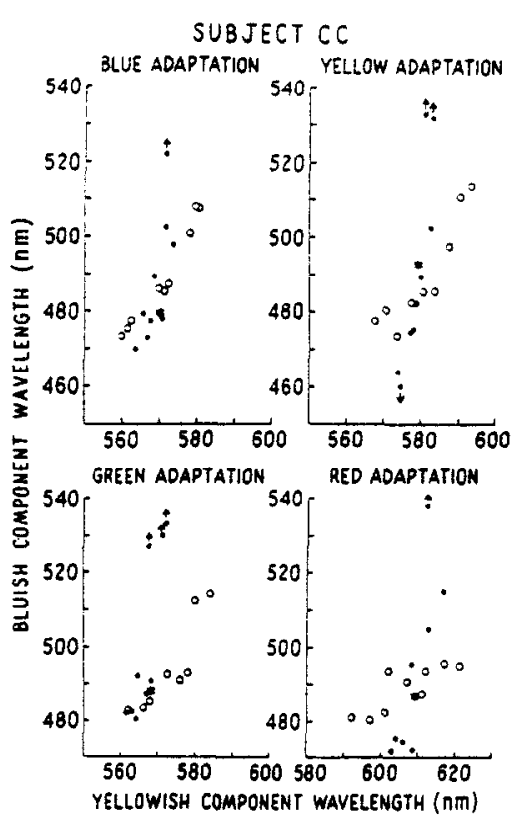

Fig. 2. The loci of yellow plus blue mixtures that are neither reddish nor greenish when viewed under 40 td of equilibrium blue, equilibrium yellow, equilibrium green and red $(650 \mathrm{~nm})$ adaptation for subject $\mathrm{CC}$ are shown. Closed circles are the results for a yellow:blue ratio of 6.8 and open circles for a ratio of 2.0 . Poorly determined points are marked by arrows.

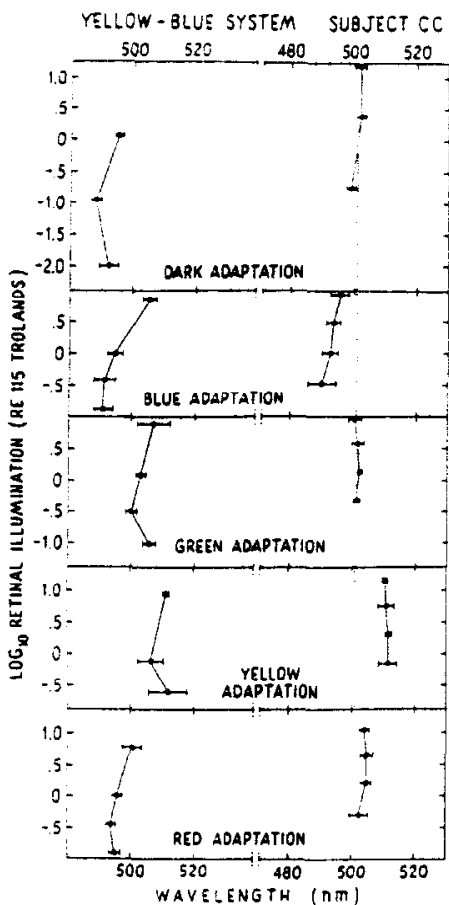

Fig. 3. The mean values of equilibrium green (right) and the blue component of equilibrium red (left) spectral loci under dark adaptation, blue adaptation, green adaptation and red adaptation are shown for subject CC. Note the break in the wavelength abscissa. (Details are as in Fig. 1.)

Table 3. Equilibrium colors of the yellow/blue opponent process

\begin{tabular}{|c|c|c|c|c|c|c|c|c|c|c|}
\hline \multirow{3}{*}{\multicolumn{2}{|c|}{ Subject }} & \multicolumn{9}{|c|}{ Adapting Condition } \\
\hline & & \multirow{2}{*}{$\frac{\text { Dark }}{\lambda_{e}}$} & \multicolumn{2}{|r|}{ Btue } & \multicolumn{2}{|r|}{ Green } & \multicolumn{2}{|r|}{ Yellow } & \multicolumn{2}{|r|}{ Red } \\
\hline & & & $\log I$ & $\lambda_{0}$ & $\log I$ & $\lambda_{e}$ & log I & $\lambda_{e}$ & $\log 1$ & $\lambda_{0}$ \\
\hline \multirow{4}{*}{ 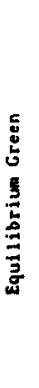 } & DK & $\begin{array}{l}510.0 \\
509.2 \\
507.6 \\
508.0\end{array}$ & $\begin{array}{l}1.15 \\
.66 \\
.15 \\
. .21\end{array}$ & $\begin{array}{l}509.3 \pm 0.8 \\
506.0 \pm 4.4 \\
502.7 \pm 3.1 \\
497.7 \pm 7.9\end{array}$ & $\begin{array}{r}1.14 \\
.72 \\
.23 \\
-.22\end{array}$ & $\begin{array}{l}509.0 \pm 1.1 \\
509.0 \pm 1.1 \\
507.1 \pm 1.4 \\
507.1 \pm 1.0\end{array}$ & $\begin{array}{r}1.34 \\
.90 \\
.44 \\
. .03\end{array}$ & $\begin{array}{l}519.6 \pm 2.2 \\
518.4=3.2 \\
517.8=3.2 \\
521.5 \pm 5.0\end{array}$ & $\begin{array}{r}1.26 \\
.80 \\
.3 .3 \\
-.05\end{array}$ & $\begin{array}{l}515.0 \pm 1.9 \\
513.1=2.3 \\
512.5 \pm 2.1 \\
510.3 \pm 4.2\end{array}$ \\
\hline & $\pi$ & $\begin{array}{l}494.8 \\
493.3 \\
490.1\end{array}$ & $\begin{array}{r}.77 \\
.30 \\
-.26 \\
-.71\end{array}$ & $\begin{array}{l}483.8 \pm 1.7 \\
481.5 \pm 2.1 \\
478.1 \pm 1.3 \\
478.3 \pm 1.8\end{array}$ & $\begin{array}{r}.90 \\
.48 \\
-.01 \\
-.46\end{array}$ & $\begin{array}{l}493.1 \pm 2.1 \\
494.0 \pm 1.9 \\
490.8 \pm 1.0 \\
491.3 \pm 1.2\end{array}$ & $\begin{array}{r}1.02 \\
.54 \\
.09 \\
-. .31\end{array}$ & $\begin{array}{l}502.2 \pm 1.7 \\
499.2 \pm 3.3 \\
499.3 \pm 3.6 \\
501.9 \pm 4.8\end{array}$ & $\begin{array}{r}.89 \\
.47 \\
-.01 \\
-.46\end{array}$ & $\begin{array}{l}492.2 \pm 1.3 \\
403.7=2.7 \\
491.3 \pm 3.6 \\
491.5 \pm 3.3\end{array}$ \\
\hline & PS & $\begin{array}{l}497.8 \\
496.2 \\
494.5 \\
494.5\end{array}$ & $\begin{array}{r}.90 \\
.96 \\
.00 \\
-.90\end{array}$ & $\begin{array}{l}493.5 \pm 2.2 \\
492.3 \pm 0.4 \\
491.0 \pm 1.9 \\
488.3 \pm 0.5\end{array}$ & $\begin{array}{r}.95 \\
.50 \\
.00 \\
-.45\end{array}$ & $\begin{array}{l}497.1 \pm 0.4 \\
495.8 \pm 1.4 \\
492.1 \pm 0.4 \\
492.4 \pm 0.6\end{array}$ & $\begin{array}{r}.98 \\
.52 \\
.06 \\
-.39\end{array}$ & $\begin{array}{l}500.4 \pm 1.8 \\
497.5 \pm 1.5 \\
496.7 \pm 1.8 \\
497.0=1.9\end{array}$ & $\begin{array}{r}.96 \\
.52 \\
.05 \\
-.39\end{array}$ & $\begin{array}{l}498.1 \pm 0.4 \\
497.4 \pm 1.1 \\
496.1 \pm 1.7 \\
496.6 \pm 1.7\end{array}$ \\
\hline & $\mathrm{cc}$ & $\begin{array}{r}502 \\
502 \\
499 \\
.\end{array}$ & $\begin{array}{r}.93 \\
.47 \\
.01 \\
-.48\end{array}$ & $\begin{array}{l}495.5 \pm 2.8 \\
493.4 \pm 2.2 \\
492.5 \pm 2.6 \\
490.0 \pm 4.6\end{array}$ & $\begin{array}{r}.99 \\
.58 \\
.14 \\
-.33\end{array}$ & $\begin{array}{l}500.5 \pm 2.2 \\
501.5 \pm 2.1 \\
501.9 \pm 0.8 \\
500.8 \pm 1.0\end{array}$ & $\begin{array}{r}1.17 \\
.75 \\
.32 \\
-. .14\end{array}$ & $\begin{array}{l}510.5=0.5 \\
510.6=2.8 \\
511.6 \pm 0.8 \\
511.4 \pm 2.9\end{array}$ & $\begin{array}{r}1.05 \\
.64 \\
.20 \\
-.30\end{array}$ & $\begin{array}{l}503.8 \pm 1.7 \\
504.9 \pm 1.8 \\
505.1 \pm 1.5 \\
502.5 \pm 2.8\end{array}$ \\
\hline \multirow{4}{*}{ 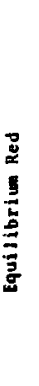 } & ox & $\begin{array}{l}499.3 \\
495.1 \\
493.7 \\
490.2\end{array}$ & $\begin{array}{r}.75 \\
-.01 \\
-.44 \\
-.87\end{array}$ & $\begin{array}{l}499.3 \pm 3.3 \\
495.2 \pm 1.9 \\
492.7 \pm 0.8 \\
491.0 \pm 6.1\end{array}$ & $\begin{array}{r}.83 \\
-.02 \\
-.47 \\
-.91\end{array}$ & $\begin{array}{l}504.0 \pm 2.8 \\
496.8 \pm 1.1 \\
497.1 \pm 1.2 \\
496.5 \pm 4.2\end{array}$ & $\begin{array}{r}.94 \\
-.06 \\
-.54 \\
-1.00\end{array}$ & $\begin{array}{l}509.6 \pm 2.9 \\
500.9 \pm 2.5 \\
504.0 \pm 5.1 \\
506.1 \pm 4.6\end{array}$ & $\begin{array}{r}.80 \\
-.03 \\
-.46 \\
-.92\end{array}$ & $\begin{array}{l}501.9 \pm 1.4 \\
497.7 \pm 6.3 \\
496.0 \pm 7.1 \\
497.7 \pm 7.9\end{array}$ \\
\hline & $\pi$ & $\begin{array}{l}480.5 \\
474.3 \\
470.4 \\
.\end{array}$ & $\begin{array}{r}.27 \\
.04 \\
-.41 \\
-.87\end{array}$ & $\begin{array}{l}475.5 \pm 2.2 \\
475.3 \pm 2.9 \\
475.0 \pm 2.7 \\
473.5 \pm 3.3\end{array}$ & $\begin{array}{r}.57 \\
.06 \\
-.39 \\
-.84\end{array}$ & $\begin{array}{l}485.5 \pm 2.2 \\
483.1 \pm 3.1 \\
483.3 \pm 3.2 \\
482.1 \pm 2.1\end{array}$ & $\begin{array}{r}.73 \\
-.08 \\
-.43 \\
-.89\end{array}$ & $\begin{array}{l}497.2 \pm 1.7 \\
496.5 \pm 4.0 \\
492.0 \pm 3.5 \\
493.8 \pm 3.2\end{array}$ & $\begin{array}{r}.64 \\
.04 \\
-.41 \\
-.85\end{array}$ & $\begin{array}{l}490.2 \geq 1.8 \\
487.1 \pm 1.6 \\
487.1 \geq 0.9 \\
485.5 \pm 1.3\end{array}$ \\
\hline & PS & $\begin{array}{l}504.1 \\
496.6 \\
497.8 \\
507.5\end{array}$ & $\begin{array}{r}.78 \\
.00 \\
-.43 \\
-.88\end{array}$ & $\begin{array}{l}501.2 \pm 1.5 \\
493.7 \pm 0.1 \\
492.2 \pm 2.6 \\
491.6 \pm 2.3\end{array}$ & $\begin{array}{r}.86 \\
-.02 \\
-.47 \\
-.90\end{array}$ & $\begin{array}{l}505.2 \pm 1.4 \\
496.4 \pm 0.8 \\
496.4 \pm 1.6 \\
495.4 \pm 2.4\end{array}$ & $\begin{array}{r}.91 \\
-.05 \\
-.54 \\
-.98\end{array}$ & $\begin{array}{l}508.2 \pm 0.4 \\
500.4 \pm 2.0 \\
504.0 \pm 3.1 \\
503.5\end{array}$ & $\begin{array}{r}.81 \\
.00 \\
-.45 \\
-.90\end{array}$ & $\begin{array}{l}502.6 \pm 2.7 \\
494.1 \pm 1.7 \\
494.4 \pm 2.8 \\
495.1 \pm 4.7\end{array}$ \\
\hline & cc & $\begin{array}{r}495.3 \\
488.5 \\
492.3\end{array}$ & $\begin{array}{r}. .86 \\
-.01 \\
-.43 \\
-.87\end{array}$ & $\begin{array}{l}505.5 \pm 2.2 \\
494.6 \pm 2.5 \\
491.3 \pm 3.6 \\
490.8 \pm 3.3\end{array}$ & $\begin{array}{r}.89 \\
-.08 \\
-.49 \\
-101\end{array}$ & $\begin{array}{l}507.2 \pm 5.3 \\
502.8 \pm 1.4 \\
500.0 \pm 1.7 \\
506.4 \pm 2.2\end{array}$ & $\begin{array}{c}.94 \\
-.12 \\
-.60 \\
=\end{array}$ & $\begin{array}{c}511.3 \pm 1.1 \\
506.4 \pm 4.2 \\
512.2 \pm 6.1 \\
?\end{array}$ & $\begin{array}{r}.77 \\
-.02 \\
-.45 \\
-.90\end{array}$ & $\begin{array}{l}500.5 \pm 3.3 \\
495.5 \pm 1.5 \\
493.9 \pm 1.5 \\
495.0 \pm 1.7\end{array}$ \\
\hline
\end{tabular}

$\lambda_{g}$ is the mean equilibrium wavelength ( \pm halfwidth of $80 \%$ confidence interval). $\log l$ is the logarithm of the retinal illumination (relative to $115 \mathrm{td}$ ). Adapting luminance is $40 \mathrm{td}$ 


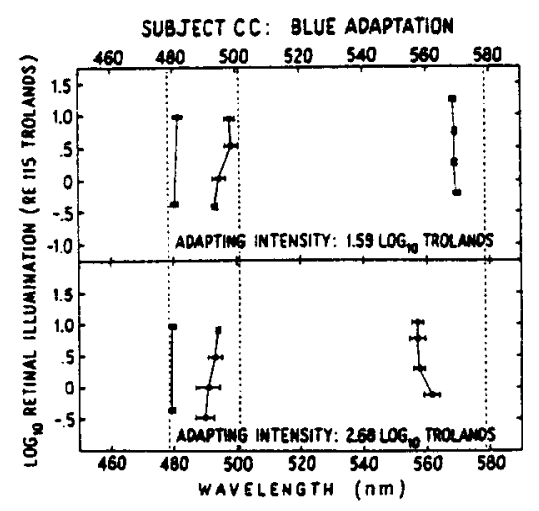

Fig. 4. The mean values of equilibrium blue, equilibrium green, and equilibrium yellow spectral loci under 1.59 and $2.68 \mathrm{log}$ td of blue adaptation are shown for subject CC. The dotted lines mark the mean dark-adapted values. The error bars are 80 per cent confidence intervals. The data shown at $1.59 \log$ td are not the same as in Figs. 1 and 3 but were obtained in Experiment II as a replication under the same adapting condition as in Experiment $I$.

dark-adapted value marked by the left-most dotted line. Equilibrium green was shifted toward shorter wavelengths, approx $5 \mathrm{~nm}$ at $1.59 \mathrm{log}$ td and $10 \mathrm{~nm}$ at $2.68 \mathrm{log}$ td. There is a slight hint of nonlinearity which was also present at 40 td of blue adaptation (see Fig. 3). At $1.59 \mathrm{log}$ td the equilibrium yellow locus was shifted approx $11 \mathrm{~nm}$; at $2.68 \mathrm{log}$ td the shift was more than $20 \mathrm{~nm}$. Yet linearity was maintained.

The results with green adaptation were similar in that linearity was largely maintained while substantial shifts in the equilibrium loci were observed (see Fig. 5). The equilibrium blue locus was shifted approx $10 \mathrm{~nm}$ under an adapting intensity of $1.59 \log$ td and more than $15 \mathrm{~nm}$ at both 2.64 and $3.39 \mathrm{log}$ td. The indication of nonlinearity at $2.64 \log \mathrm{td}$ is countered by clearly linear results at 1.59 and 3.39 $\log t d$. The yellow locus showed even more dramatic shifts with green adaptation. At $1.59 \mathrm{log}$ td a shift of $9 \mathrm{~nm}$ was seen; at $2.64 \log$ td there was a shift of $20 \mathrm{~nm}$; and at $3.39 \mathrm{log}$ td the shift was $25 \mathrm{~nm}$. The higher the adapting intensity, the greater was the shift in the equilibrium loci. Even with a $25-\mathrm{nm}$ shift in the equilibrium yellow locus under green adaptation linearity was clearly maintained.

Under high level yellow adaptation the character of the results was very different. As Fig. 6 shows, at $1.59 \log$ td adaptation, the linearity observed under dark-adaptation was preserved. The locus of equilibrium yellow was unchanged, while shifts of more than 10 and $7 \mathrm{~nm}$ were observed for the equilibrium blue and green loci, respectively. At the two highest adapting levels, however, definite nonlinearities were evidenced. At high test intensities, the equilibrium yellow locus was identical with its dark-adapted value. At low test intensities there were shifts greater than $10 \mathrm{~nm}$. The equilibrium blue and green results under 2.82 and $3.61 \mathrm{log}$ td of yellow adaptation showed marked nonlinearities. The results showed large undetermined shifts away from the dark-adapted values.

Our main interest in Experiment II was to press the limits of our linearity findings as the luminance of the adapting light was increased. Since red

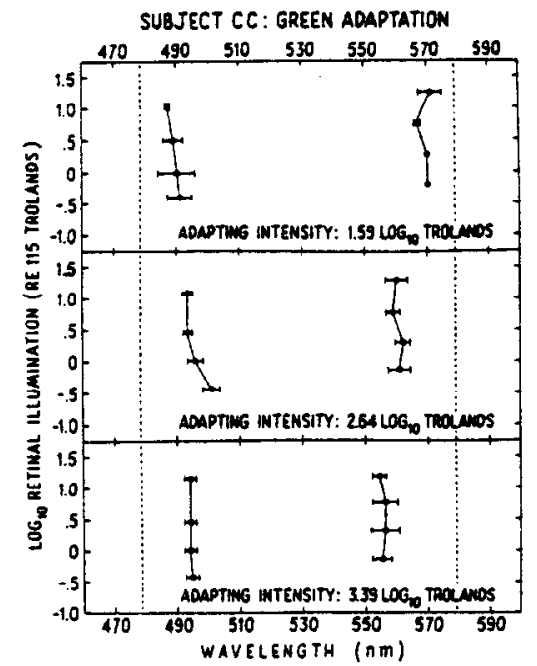

Fig. 5. The mean values of the equilibrium blue and equilibrium yellow spectral loci under green adaptation of 1.59 . $2.64,3.39 \mathrm{log}$ td are shown for subject CC. At $1.59 \mathrm{log}$ td of green adaptation error bars are omitted when the between-session variability was zero. (Details are as in Fig. 4.)

adaptation of $40 \mathrm{td}$ produced systematic nonlinearities in Experiment I, we omitted higher levels of red adaptation.

\section{DISCUSSION}

Characterization of red/green equilibrium changes with adaptation

The effect of low to moderate levels of chromatic adaptation on the red/green system is to produce large shifts in the loci of the equilibrium hues (except when the adapting and test lights are of the same wavelength). At the same time, the yellow and blue equilibria are (1) approximately invariant with

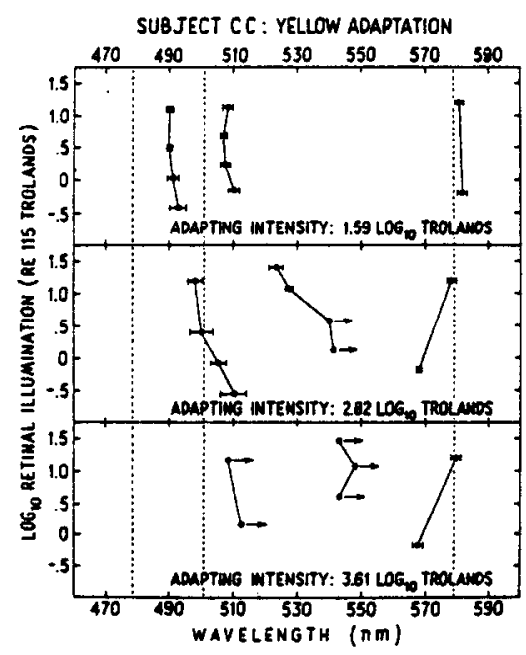

Fig. 6. The mean values of the equilibrium blue, green and yellow spectral loci under yellow adaptation of 1.59 , 2.82 and $3.61 \mathrm{log}$ td are shown for subject CC. Poorly determined points are marked by arrows. (Details are as in Fig. 4.) 
changes in test luminance (Fig. 1) and 12) approximately additive (Fig. 2). Confirmation of the invariance and additivity properties implies that the red green chromatic-response function can be defined. independent of luminance, for the chromatically adapted eye, and that it remains a linear combination of the photopigment quantum catches (equation (2)). The dependence of the coefficients $k_{1 j}$ (c) on the adapting light $c$ specifies the changes in the chromaticresponse function.

In general there are two kinds of questions about chromatic adaptation: Where is the source of the controlling signal. and where is the site of its action? Here we describe adaptation by the coefficients $k_{1},(c)$. The question of the source of the controlling signal deals with how $k_{1},(c)$ depends on light $c$. The question of site of action deals with whether the location of effect is in the receptors themselves or at the receptorto-opponent linkage. (In the latter case this means that the coefficients characterizing adaptation to light $c$ may be different for the different opponent systems.) In this section we show that our data permit a surprising inference about the source of chromatic adaptation.

The simplest hypothesis is that the $j$ th coefficient depends only on the quantum catch of the $j$ th photopigment for light $c$. This hypothesis corresponds to the idea that the source of the adapting or gainchange signal lies in the receptor. At the opposite extreme we have the most general possibility, that a given coefficient $k_{1 j}(c)$ depends on $x(c) . \beta(c)$, and $\gamma(c)$. (Nothing more general need be considered, since metameric lights produce the same chromatic adaptation.)

The first possibility was suggested by von Kries (1905) in connection with his coefficient law of adaptation; it is suggested further by Brindley's work (1959), in which colored afterimages produced by brief, bright flashes were shown to depend on photopigment bleaches rather than on perceived color. Pointing in the opposite direction is the work of Loomis $(1971,1972)$, who showed that for his moderate adapting conditions, colored afterimages depended on perceived color and are independent of amount of pigment bleached. Loomis conditions (moderate intensity and long duration of adapting light) are more similar than Brindley's to the conditions used in the present experiment.

We are able to reject the simple, intrareceptor model on the basis of a mathematical argument. The one additional assumption required is the following:

Self-invariance: A dark-adapted red/green equilibrium light remains in red/green equilibrium under self-adaptation.

This principle is supported by our data on adaptation to individually adjusted equilibrium blue or equilibrium yellow lights; such adaptation left the blue or yellow locus invariant, respectively. A similar conclusion was reached by Wooten (1970); and indeed, the self-invariance assumption relates to the common observation that prolonged inspection of a light of moderate intensity does not produce a hue change.

Incompatibility theorem: Consider the following conditions: (a) Red green equilibrium of light $a$ after adaptation to $c$ is described by $\phi_{1}(a ; c)=0$. where $\phi_{1}(a ; c)$ satisfies equation (2).

(b) $k_{1 i}(c)=y_{1}[x(c)] . \quad k_{12}(c)=g:[\beta(c)], \quad k_{13}(c)=$ $g_{3}[;(c)]$.

(c) $\phi_{1}(c: 0)=0$ if and only if $\phi_{1}(c ; c)=0$.

These conditions are incompatible unless $k_{1 j}=1$ for all c. i.e. no adaptation takes place.

Proof. Without loss of generality adjust the units for $x, \beta, y$ such that $k_{1},(0)=1$. i.e. for the dark-adapted case we have

$$
\phi(a ; 0)=z(a)-\beta(a)+\gamma(a) .
$$

Then the condition for dark-adapted red green equilibrium is simply $\beta=x+\because$. From condition (c). Whenever we have a light that satisfies this condition. we also have

$$
g_{1}(x) \alpha-g_{2}(\beta) \beta+g_{3}(y) j=0 \text {. }
$$

i.e.

$$
(x+i) g_{2}(x+y)=x g_{1}(x)+i g_{3}(i)
$$

Equation (3) is a generalization of the well-known Cauchy functional equation. It is valid in a convex cone in the $(x, y)$ plane. Thus the only solutions to (3) are given by

$$
\xi g,(\xi)=\delta \dot{s}+\epsilon_{j}
$$

(where $\epsilon_{1}+\epsilon_{3}=\epsilon_{2}$ ). Letting $\xi=0$ shows that $\epsilon_{j}=0, j=$ $1,2,3$. Thus $g_{j}(\xi)=\delta$. a constant. Since $g_{j}(0)=1$ by assumption, we have $k_{1}(c)=1$ for all $c$, as claimed in the theorem.

QED

An intuitive grasp of this theorem is perhaps best obtained by considering the case of equilibrium blue. Under dark adaptation, at 475 or $480 \mathrm{~nm}$, the negative value of $-k_{12} \beta+k_{13} \gamma$ (greenness) is balanced by a positive $k_{11} x$ input. If chromatic adaptation of a cone system depends on that cone's quantum catch, then under equilibrium blue adaptation, one would expect $g_{2}(\beta) / g_{1}(x)$ and $g_{3} \gamma / g_{1}(\alpha)$ to be greater than unity. Thus the net greenness produced by the middleand long-wavelength cones would be enhanced relative to the balancing redness. Equilibrium blue ought to turn blue-green under self-adaptation. The fact that it does not do so suggests that signals originating in the $\alpha$ cones, feeding perhaps through the yellowblue response system, eventually are fed back to reduce the inputs from $\beta$ and $\gamma$ cones to the red/green system.

Note that assumptions (a) and (c) of the incompatibility theorem follow from the generalizations established in the experiments described above; (a) from linearity, (c) from self-invariance. Therefore it is (b) which must be rejected-at least one of the coefficients $k_{1},(c)$ depends on more than one cone response.

Two of the major concepts invoked to explain chromatic adaptation or successive contrast are receptor gain changes and opponent induction. Our results show that under the present conditions, much of the effect can be accounted for in terms of receptor gain changes (coefficient law) although with a complication as mentioned in the preceding theorem. Hurvich and Jameson (1959) offer a theory that can have both coefficient changes and an inducation term. But our results leave little room for the induction term, though of course it comes into play under other conditions (Hurvich and Jameson. 1958). Note that a pure opponent-induction model would predict that adaptation to any equilibrium light should not affect 
the equilibrium locus of that light or of its complement. For example, equilibrium blue adaptation should leave not only the locus of equilibrium blue unchanged but should also leave the locus of equilibrium yellow untouched. Figures 1 and 3 show that this prediction was not supported; equilibrium lights remain unmoved under self-adaptation, but their complements show large shifts. The directions of these shifts (and of all other shifts) are qualitatively consistent with a receptor gain-reduction model. A blue adapting light should depress the sensitivity of the short wavelength cones more than that of the middle wavelength cones while affecting the long wavelength cones least. Thus the previous equilibrium yellow light should look reddish, and a shift to shorter wavelengths should be the result. This is confirmed in Fig. 1 and Table 1. For CC the shift caused by blue adaptation was $9 \mathrm{~nm}$, from 579 to 570 ; for PS the shift was $15 \mathrm{~nm}$, for DK $21 \mathrm{~nm}$, for TC $35 \mathrm{~nm}$. We conclude, as did Wooten (1970), that opponent induc. tion alone does not suffice as a theory of these adaptation effects.

Figures 4 and 5 show that the results discussed thus far hold remarkably well for adaptation to blue and green lights up to 500 and 2500 td, respectively.

Another important result of these experiments stems from the change in equilibrium blue locus under red or yellow adaptation. As Figs. 1 and 6 show, under long-wavelength adaptation the former equilibrium blue wavelength looks reddish-blue. Recall the $\mathrm{red} / \mathrm{green}$ chromatic response function, equation (1)

$$
\phi_{1}(a)=k_{11} x(a)-k_{12} \beta(a)+k_{13} \gamma(a),
$$

which allows $k_{11} \geq 0$. Indeed, suppose $k_{11}=0$, then equilibrium blue should remain unchanged under adaptation to equilibrium yellow (since equilibrium yeliow is unchanged under self-adaptation). By the same argument it should appear greenish under red adaptation just as does equilibrium yellow. These are inconsistent with our results. Therefore, $k_{11}$ must be positive. This means the short-wavelength cones provide input to both opponent systems, and in particuJar, a red input to the red/green opponent system. Assuming that long-wavelength adaptation leaves the output of the $\alpha$ cones enhanced relative to the $\beta$ and $\gamma$ cones implies that equilibrium blue should look reddish under long-wavelength adaptation; and it does.

Under higher level yellow adaptation exceeding $40 \mathrm{td}$, however, the linearity and self-adaptation principles no longer hold (Fig. 6). This means that under yellow adaptation of high intensities, opponent-process equilibria must be described by a nonlinear function. The fact that under dark adaptation the red/ green equilibrium code is linear while under conditions of high intensity yellow adaptation it must be nonlinear indicates that we cannot account for high intensity yellow adaptation by a simple model of gain changes in the cone outputs. This constitutes a more serious departure from the simple von Kries scheme than previously discussed. At low levels of unique blue, green and yellow lights, a von Kries kind of scheme holds as long as we allow the coefficients $k_{1 j}$ to be dependent on the absorptions in more than one cone type. For blue and green adaptation this scheme holds up to 500 and 2500 td, respectively. For yellow adaptation, however, a model of gain changes in the cone outputs no longer works, even if each $k_{1 j}$ is allowed to be dependent on all three cone types.

Characterization of changes in other opponent-systems with adaptation

The nonlinearity of the yellow/blue opponent system (Larimer et al., 1975) makes precise characterization difficult. However, the data in Fig. 3 and Table 3 indicate that there is no profound qualitative change under adaptation. The green equilibrium locus shifts but remains nearly invariant with luminance; the non-invariance of the red equilibrium is not much changed by adaptation. It is therefore plausible to suppose that the shifts in yellow/blue equilibrium can also be characterized by gain changes.

We have no data relevant to the third, or white/ black opponent system. One relevant question would be whether the Grassmann-additivity results obtained by minimizing flicker or contrast (see Boynton and Kaiser, 1968) are maintained after chromatic adaptation.

\section{Estimation of coefficients}

Our results allowed us to estimate the adaptation coefficients $k_{i}(c)$. The theoretical calculations were somewhat speculative, and we pursue this topic in the Appendix.

\section{Relation to asymmetric matching}

Most previous work on chromatic adaptation has used one or another version of asymmetric (crosscontext) visual colorimetry. Our results seem to support a modified von Kries coefficient scheme, whereas previous studies using asymmetric matching have mainly rejected the coefficient scheme; we need, therefore, to analyze the relationship between results of asymmetric matches and of equilibrium determinations. In fact, the relationship between the two types of experiments is quite subtle, and there is no necessary contradiction between results supporting a coefficient scheme for linear opponent-process codes and results rejecting a coefficient scheme for asymmetric matching.

Three points need to be discussed: (i) the differences in adapting conditions from previous studies; (ii) the functional relation between linear opponent-process codes and perceptual codes; and (iii) the possible adaptation-dependence of this functional relation.

Differences in experimental methodology are not essential to the experimental logic; however, differences in the intensity of the adapting light may have profound effects. We have shown in these experiments that the coefficient scheme fails to describe the red/ green equilibria at high levels (660 and 4080 td) of yellow adaptation, whereas it succeeds (except for red adaptation) at a low level $(40 \mathrm{td})$. Previous studies using asymmetric matching have mainly rejected the coefficient scheme on the basis of data obtained at moderate to high levels of adapting intensities. For example, Walters (1942) used green adaptation of 600 and $1200 \mathrm{td}$ and red adaptation of 1000 and $2000 \mathrm{td}$. MacAdam (1956) used adapting lights between 1500 and 2500 td for the bulk of his experiments. Whether the coefficient law succeeds in describing asymmetric matching under low levels of chromatic adaptation is still an open question. 
What we mean by a "perceptual code" coincides with what Jameson and Hurvich (1961) call a "chromatic response process" and Stiles (1967) calls a "mechanism". This is a physiologically or operationally defined measure which is equated whenever two colors match. Thus, a match between light $a$. viewed after adaptation to $c$, and light $b$, with adaptation to $d$, is equivalent to three equations between independent perceptual codes $f_{1}, f_{2}, f_{3}$ :

$$
\begin{aligned}
& f_{1}(a: c)=f_{1}(b ; d) \\
& f_{2}(a ; c)=f_{2}(b ; c) \\
& f_{3}(a ; c)=f_{3}(b ; d) .
\end{aligned}
$$

In an opponent-colors framework $f_{1}$ would be the magnitude of perceived redness or greenness, $f_{2}$ the perceived yellowness or blueness, and $f_{3}$ the perceived whiteness or blackness.

What is the relationship of perceptual codes $f_{1}, f_{2}$, $f_{3}$ to three functions such as $\phi_{1}, \phi_{2}, \phi_{3}$ based on opponent-cancellation methods (for $\phi_{1}$ and $\phi_{2}$ ) or on additive luminance $\left(\phi_{3}\right)$ ?

If $f_{1}$ (perceived red green) were a fixed function of $\phi_{1}$ (red/green chromatic response) then $\phi_{1}$ matches would predict $f_{1}$ matches. Thus, at least one aspect of asymmetric matching could be predicted by a coefficient scheme. If similar properties held for $f_{2}, \phi_{2}$ and $f_{3}, \phi_{3}$ then complete asymmetric matches would be predicted by the coefficient scheme. Under these simplified assumptions, the equilibrium experiments and the asymmetric matching experiments would be very closely interrelated.

However, we know on other grounds that perceived redness/greenness is not a simple function of the red/ green chromatic-response. For example, addition of achromatic light leaves $\phi_{1}$ unchanged (since $\phi_{1}=0$ for an achromatic light) but reduces the perceived redness or greenness.

There is necessarily a functional relationship between $f_{j}$ and $\phi_{1}, \phi_{2}$, and $\phi_{3}$. It can be written as follows:

$$
f_{j}(a ; c)=F_{j}\left[\phi_{1}(a ; c), \phi_{2}(a ; c), \phi_{3}(a ; c) ; c\right] .
$$

The reason for the existence of such a functional relationship is that, if $\phi_{k}(a ; c)=\phi_{k}(b ; c)$ for $k=1,2,3$ then $a$ and $b$ are metameric and $a$ fortiori they match with respect to every perceptual code. There is nothing in the logic of the equilibrium or asymmetric matching experiments that prevents the functional relation between $f_{j}$ and the $\phi$ 's from depending on the adapting condition $c$. (Such a dependence could perhaps be interpreted in terms of additional, proximal sites of chromatic adaptation.) If, in fact, the relation between each perceptual code and the three $\phi$ 's is independent of adaptation, then asymmetric matches correspond to $\phi$ matches. In such a case, a coefficient scheme for all three $\phi$ functions would lead to a coefficient scheme for asymmetric matches.

In other words, if the coefficient scheme describes not only the red/green equilibria, but also the yellow/ blue equilibria and white/black, as a function of chromatic adaptation, and if, under the same adaptation conditions, the coefficient scheme fails to describe asymmetric matching, we would be forced to the conclusion that the relationship between perceptual codes and the $\phi$ 's is adaptation-dependent. This would imply that the relationship between perceptual codes and photopigments was nonlinear. and that the nonlinearity is systematically adaptation-dependent. Since we have not established the coefficient scheme for white black, nor very firmly for yellow blue, and since there are residual questions about similarity of adaptation conditions. such a conclusion would be premature on the basis of the present data.

There is one case for which the similarity of adapting conditions between our study and previous studies on asymmetric matching allows a comparison. We found that under green adaptation of approx 450 and 2500 td. the red green equilibria follow a coeffcient scheme. Under similar levels of green adaptation Walters (1942) and MacAdam (1956) found that the coefficient law fails for asymmetric matching. Although the yellow blue and black/white equilibria have not been investigated at these higher adapting intensities, we have a hint that the functions $F_{j}$ must be adaptation-dependent

\section{REFERENCES}

Boynton R. M. and Kaiser P. K. (1968) Vision: the additivity law made to work for heterochromatic photometry with bipartite fields. Science 161. 366-368.

Brindley G. S. (1959) The discrimination of afterimages. J. Physiol. Lond. 147. 194-203.

Brindley G. S. (1960) Two more visual theorems. Q. Jl exp. Psichol. 12. 110-112.

Burnham R. W., Evans R. M. and Newhall S. (1957) Prediction of color appearance with different adaptation illuminations. J. opt. Soc. Am. 47, 35-42.

Hurvich L. M. and Jameson D. (1958) Further development of a quantified opponent-colors theory. In Teddington, England National Physical Laboratory Symposium No. 8. Visual Prohlems of Color. H.M.S.O.

Jameson D. and Hurvich L. M. (1955) Some quantitative aspects of an opponent-colors theory-I: Chromatic responses and spectral saturation. J. opt. Soc. Am. 45, 546552

Jameson D. and Hurvich L. M. (1961) Opponent chromatic induction: experimental evaluation and theoretical account. J. opt. Soc. Am. 51. 46-53.

Krantz D. H. (1975a) Color measurement and color theory-I. Grassmann structures. J. math. Psychol. 11 (in press).

Krantz D. H. (1975b) Color measurement and color theory -II. Opponent-colors theory. J. math. Psychol. 11 (in press).

von Kries J. (1905) Die Gesichtsempfindungen. In Handbuch der Physiologie der Menschen (Edited by Nagel W.). Springer, Berlin.

Larimer J., Krantz D. H. and Cicerone C. M. (1974) Opponent-process additivity-I: Red/green equilibria. Vision Res. 14, 1127-1140.

Larimer J.. Kraniz D. H. and Cicerone C. M. (1975) Opponent-process additivity-II: Yellow/blue equilibria and nonlinear models. Vision Res. 15. 723-731.

Loomis J. M. (1971) Studies of chromatic adaptation using afterimage matching. Doctoral dissertation, University of Michigan.

Loomis J. M. (1972) The photopigment bleaching hypothesis of complementary after-images: a psychophysical test. Vision Res. 12. 1587-1594.

MacAdam D. L. (1956) Chromatic adaptation. J. opt. Soc. Am. 46. 500-513.

Stiles W. S. (1967) Mechanism concepts in color theory. $J$. of the Color Group 11. 106-123. 
Vos J. J. and Walraven P. L. (1971) On the derivation of the foveal receptor primaries. Vision Res. 11, 799-818.

Walters H. V. (1942) Some experiments on the trichromatic theory of vision. Proc. R. Soc. B131, 27-50.

Wooten B. (1970) The effects of simultaneous and successive chromatic contrast on spectral hue. Doctoral dissertation, Brown University.

\section{APPENDIX}

\section{Estimation of coefficients}

Our results allow us to estimate the adaptation coeffcients $k_{1}(c)$ as follows: Under each adapting condition $c$, two red/green equilibrium wavelengths were determined, one short-wavelength value and one long-wavelength value (Figs. 1, 4 and 5). For each determination. equation (2) yields a homogeneous equation in the unknowns $k_{1}(c)$. For example, if $478 \mathrm{~nm}$ is found to be an equilibrium point for a given observer, then we have the equation

$$
x_{478} k_{11}-\beta_{478} k_{12}+y_{478} k_{13}=0 \text {. }
$$

We used values of $x(a), \beta(a), \gamma(a)$ taken from Vos and Walraven (1971). The two simultaneous equations in three unknowns $k_{1 j}$ permitted us to solve for the two ratios $k_{11} / k_{13}$ and $k_{12} / k_{13}$. We divided these ratios by their dark adapted values (this is the same as choosing units for $x, \beta, \gamma$ such that the dark-adapted chromatic-response function is $x-\beta+\eta)$.

The normalized values of $k_{11} / k_{13}$ and $k_{12} / k_{13}$ are shown in Table 4. They are reasonable according to a receptor gain-reduction model. For example, under green adaptation, the middle-wavelength cone output is depressed relative to the long-wavelength output $\left(k_{12} /\right.$ $k_{13}<1$ ). At the same time the short-wavelength output is enhanced relative to the long-wavelength output $\left(k_{11}\right)$ $k_{13}>1$ ).

We can go one step further by applying the yellow/blue system data to our estimation scheme. Larimer et al. (1975)

Table 4. Estimated adaptation coefficients for the $\mathrm{red} / \mathrm{green}$ equilibrium code under low-level $(40 \mathrm{td})$ chromatic adaptation

\begin{tabular}{|c|c|c|c|c|c|}
\hline \multirow{2}{*}{$\begin{array}{l}\text { Norals 12ed } \\
\text { Cooffietent }\end{array}$} & \multirow[b]{2}{*}{ Subject } & \multicolumn{4}{|c|}{ Adepting Condition } \\
\hline & & stue & Groen & Yellow & Red \\
\hline \multirow{4}{*}{$k_{11} / k_{13}$} & BK & 0.653 & 1.334 & 1.603 & 4.205 \\
\hline & $\pi$ & 0.520 & 1.071 & 2.725 & 3.219 \\
\hline & PS & 0.796 & 0.999 & 1.488 & 1.834 \\
\hline & $\propto$ & 0.791 & 1.795 & 3.260 & 5.089 \\
\hline \multirow[t]{4}{*}{$k_{12} / k_{13}$} & $D x$ & 0.759 & 0.759 & 1.019 & 1.878 \\
\hline & $\pi$ & 0.711 & 0.706 & 0.972 & 1.772 \\
\hline & PS & 0.861 & 0.861 & 1.000 & 1.298 \\
\hline & cc & 0.067 & 0.898 & 1.041 & 1.902 \\
\hline
\end{tabular}

$k_{11}, k_{12}$ And $k_{13}$ are the coefficients describing the gain reduction in the short-, middle- and longwavelength cones, respectively. showed that the dark-adapted nonlinearities in the yellow/ blue system may be decently approximated by the equation:

$$
\phi_{2}(a)=-k_{21} x(a)+k_{22} f(a)+\left[k_{23} ;(a)\right]^{n}
$$

where $n<1$. Furthermore, we obtained parameter estimates for $k_{21}, k_{23}, k_{23}$ and $n$ by optimizing the fit to our data according to a least-squares criterion. Under a receptor gain-reduction assumption, we may rewrite the above equation to include the effect of adaptation to light $c$ as:

$$
\phi_{2}(a ; c)=-k_{21}(c) \alpha(a)+k_{22}(c) \beta(a)+\left[k_{23}(c)_{1}(a)\right]^{n} .
$$

Determinations of the green and red equilibrium yield two equations in the three unknowns $k_{2,}(c)$.

If the site of adaptation is in the receptors themselves. the same set of receptor-gain reductions should work for the red/green and yellow/blue systems. To test this hypothesis, we used the $k$ ratios obtained above and computed separate solutions for the $k$ 's themselves from each of the two yellow/blue equilibria. Under the assumption that $k_{1},(c) / k_{1},(0)=k_{2}(c) / k_{2 j}(0)=k_{j}$, equation (6) becomes:

$$
\begin{aligned}
\phi_{2}(a ; c)=-k_{21}\left[k_{1} / k_{3}\right] x(a) & +k_{22}\left[k_{2} / k_{3}\right] \beta(a) \\
& +k_{23}^{n} k_{3}^{n-1}[\gamma(a)]^{n},
\end{aligned}
$$

where the $k_{j} / k_{3}$ are the normalized ratios of the $c$ adaptation dependent coefficients which were computed from the red/green equilibrium determinations (Table 4) and where the $k_{2 j}$ and $n$ are as in equation (5). The equilib. rium green and equilibrium red determinations yield two separate solutions for $k_{3}$. If, for example, 510 is found to be an equilibrium green point for an observer. we have the following equation to solve for $k_{3}$ :

$$
\begin{aligned}
0=-k_{21}\left[k_{1} / k_{3}\right] x_{510}+k_{22}\left[k_{2} / k_{3}\right] \beta_{510} & \\
& +k_{23}^{n} k_{3}^{n}-1_{7}^{n} s_{10} .
\end{aligned}
$$

Note that for equilibrium red the $650 \mathrm{~nm}$ contribution must also be included. The values of $k_{21}, k_{22}, k_{23}^{n}$ and $n$ were obtained from Larimer et al. (1975). These were, respectively, 1, 0.0110, 0-0084, 0.7 for CC; 1, 0.0052, 0.0348, 0.7 for DK; $1,00093,0-0363,0.8$ for TC. Subject PS did not participate in Larimer et al. (1975).

This computation yielded results which were unsatisfactory in two respects. First, the computed values for $k_{3}$ were imaginary in many cases. Some real values of $k_{3}$ were highly reasonable. For example, under green adaptation (subject CC) $k_{1}>k_{3}>k_{2}$, which is a reasonable prediction from a receptor gain-change model. However. the values computed from the equilibrium green equation did not coincide well with those computed from the equilibrium red equation, even when both sets were real. These difficulties indicate that some part of the model is faulty. It is quite possible that the fault lies with the form of equation (5). This was not well determined by our previous work; among other things, our fits to the dark-adapted data (Larimer et al., 1975) modeled well the slight nonlinearities in the equilibrium red results but not the concurrent linearities of the equilibrium green results. If equation (5) is accepted, then it must be coneluded that the site of adaptation lies proximal to the receptors and that $k_{1}(c)$ $k_{1},(0) \neq k_{2},(c) / k_{2}(0)$.

For higher adapting levels the effects were larger (Figs. 4, 5 and 6) and the computed coefficients were correspondingly greater. 